\title{
BMJ Open Risks associated with managing asthma without a preventer: urgent healthcare, poor asthma control and over-the- counter reliever use in a cross-sectional population survey
}

\author{
Helen K Reddel, ${ }^{1}$ Rosario D Ampon, ${ }^{1}$ Susan M Sawyer, ${ }^{2,3,4}$ Matthew J Peters ${ }^{5}$
}

To cite: Reddel HK, Ampon RD, Sawyer SM, et al. Risks associated with managing asthma without a preventer: urgent healthcare, poor asthma control and over-the-counter reliever use in a cross-sectional population survey. BMJ Open 2017;7:e016688. doi:10.1136/ bmjopen-2017-016688

- Prepublication history and additional material for this paper are available online. To view these files please visit the journal online (http://dx.doi. org/10.1136/bmjopen-2017016688).

Received 5 March 2017 Revised 29 June 2017 Accepted 7 July 2017

\section{CrossMark}

${ }^{1}$ Woolcock Institute of Medical Research, University of Sydney, Glebe, New South Wales, Australia

${ }^{2}$ Department of Paediatrics, The University of Melbourne, Parkville, Victoria, Australia ${ }^{3}$ Murdoch Childrens Research Institute, Parkville, Victoria, Australia

${ }^{4}$ Centre for Adolescent Health, Royal Children's Hospital, Parkville, Victoria, Australia ${ }^{5}$ Department of Respiratory Medicine, Concord Hospital, Macquarie University, Sydney, New South Wales, Australia

Correspondence to

Dr Helen K Reddel;

helen.reddel@sydney.edu.au

\section{ABSTRACT}

Objectives Overuse of asthma relievers, particularly without anti-inflammatory preventers, increases asthma risks. This study aimed to identify how many reliever-only users have urgent healthcare, explore their attitudes and beliefs about asthma and its treatment, and investigate whether purchasing over-the-counter relievers was associated with worse asthma outcomes than by prescription.

Design and setting Cross-sectional population-based Internet survey in Australia

Participants of 2686 participants $\geq 16$ years with current asthma randomly drawn from a web-based panel, 1038

( $50.7 \%$ male) used only reliever medication.

Main outcome measures Urgent asthma-related healthcare; Asthma Control Test (ACT); patient attitudes about asthma and medications; reliever purchase (with/ without prescription).

Results of 1038 reliever-only participants, $23.3 \%$ had required urgent healthcare for asthma in the previous year, and only $36.0 \%$ had a non-urgent asthma review. Those needing urgent healthcare were more likely than those without such events to be male $(56.5 \%$ vs $49.0 \%, p=0.003)$ and current smokers $(29.4 \%$ vs $23.3 \%$, $\mathrm{p}=0.009$ ). Only $30.6 \%$ had well-controlled asthma (ACT $\geq 20$ ) compared with $71.0 \%$ of those with no urgent healthcare $(p<0.0001)$, and $20.8 \%$ used relievers regularly to prevent asthma symptoms (vs $5.5 \%$ of those without urgent healthcare). Those with urgent healthcare were more frustrated by their asthma and less happy with how they managed it, and they were less confident about their ability to manage worsening asthma, but just as likely as those without urgent healthcare to manage worsening asthma themselves rather than visit a doctor. Reliever-only users purchasing over-the-counter relievers were no more likely than those purchasing relievers by prescription to have uncontrolled asthma $(35.9 \%$ vs $40.6 \%, p=0.23$ ) but were less likely to have had a nonurgent asthma review.

Conclusions One-quarter of the reliever-only population had needed urgent asthma healthcare in the previous year, demonstrating the importance of identifying such patients. Their attitudes and beliefs suggest opportunities for targeting this population in the community.
Strengths and limitations of this study

- Use of rigorous web-based methodology with threestep random sampling that obtained a nationally representative population of people with asthma and a high completion rate.

- Use of a standard epidemiological definition of current asthma, and a validated symptom control tool (Asthma Control Test) allowed comparison with other studies.

- A Bonferroni correction was made to avoid overinterpretation of multiple analyses.

- As with any patient-completed survey, the diagnosis of asthma and use of healthcare services could not be confirmed objectively, and inhaler technique could not be assessed.

- Cross-sectional associations may be confounded by severity.

\section{INTRODUCTION}

The introduction of inhaled short-acting $\beta_{2}$-agonists (SABA) in the 1960s revolutionised the short-term management of asthma symptoms for patients, providing quick relief in a portable device without the substantial side effects associated with previous systemic therapies. Major national asthma guidelines still recommend that treatment of asthma should commence with as-needed SABA for symptom relief, ${ }^{12}$ commonly called 'step 1' treatment, although some now restrict this to patients with infrequent symptoms. ${ }^{1}$ For patients with persistent symptoms or a history of exacerbations, regular maintenance anti-inflammatory 'preventer' treatment, usually with inhaled corticosteroids (ICS), is recommended. ${ }^{12}$ Low-dose ICS are simple, safe and effective at reducing symptoms and, particularly, reducing the risk of serious exacerbations ${ }^{3}$ and asthma-related death. ${ }^{4}$

In the $1980 \mathrm{~s}$, overuse of SABAs was associated with an epidemic of asthma deaths in 
several countries including Australia, ${ }^{5}$ and dispensing of $\geq 12$ inhalers in a year was associated with increased risk of asthma-related death. ${ }^{6}$ However, despite more than 25 years of guideline development and messaging targeting patients and healthcare providers, it is thought that a significant proportion of those living with asthma still rely, to their detriment, on SABAs as their sole asthma treatment. Few population-level studies have examined this in detail. Using asthma control criteria based on the Global Initiative for Asthma (GINA), ${ }^{7} 50 \%$ of reliever-only participants in a study in eight Asian countries were reported to have uncontrolled asthma, and two-thirds had severe exacerbations in the previous year. ${ }^{8}$ A population-based US survey conducted in $2007^{9}$ reported that $39 \%$ of those not using preventer medication had uncontrolled asthma, based on the Asthma Control Test (ACT), ${ }^{10}$ and $31 \%$ had needed urgent healthcare in the previous year. ${ }^{11}$

Optimal care can break down at many levels. Studies in Canada $^{12}$ and Spain ${ }^{13}$ found that physicians significantly overestimate patients' level of asthma control relative to guidelines criteria. A US database study found that up to $20 \%$ of asthma patients prescribed ICS for the first time failed to have the prescription filled. ${ }^{14}$ Another survey found that fewer than one-third of asthma patients had taken a preventer medication regularly during the previous year. ${ }^{15} \mathrm{It}$ is critically important to explore underlying beliefs and attitudes to asthma that explain patient choices about medications that may not be advised by the medical community. This knowledge could inform adaptation of current community-level asthma campaigns and provide the basis for research into novel, more effective interventions.

One factor that could potentially contribute to patient use of reliever-only treatment could be the ease with which it can be obtained. In most developed countries, both reliever and preventer medications require prescriptions, but following recent proposals by the Food and Drug Administration, there was debate in the USA about making SABA available over the counter (ie, without prescription). ${ }^{16}{ }^{17}$ Although this would remove a barrier to SABA accessibility, concern has often been expressed about the appropriateness and safety of such a policy. ${ }^{1617}$ To date, no population-based data have been available from any country to provide evidence of the safety of supplying SABA without prescription. In this regard, Australia provides an interesting and topical case study because SABA has been available for purchase over the counter for asthma, without a prescription, for the past 30 years.

To address these questions, we used data from a large nationally representative survey of people with asthma in Australia $^{18}$ to examine the characteristics of those only using a reliever, identify how many had needed urgent asthma healthcare and explore their attitudes and beliefs about asthma and its treatment. We also investigated whether reliever-only users who obtained their reliever supply over the counter had compromised asthma outcomes compared with those receiving medication by prescription.

\section{METHODS}

Data were from a large cross-sectional web-based survey (online supplementary appendix 1). Methodology has been described in detail elsewhere. ${ }^{18}$ The study was approved by the Human Research Ethics Committee, Concord Hospital, NSW, and all participants provided informed consent.

\section{Survey recruitment}

Participants aged $\geq 16$ years were selected by a threestage randomised process from a large web-based panel, initially with a random invitation to complete a survey, then random presentation of a selection of screening questions, including whether they had ever had asthma, followed by standardised epidemiological screening questions for current asthma (ie, diagnosed with asthma by a health professional, and asthma symptoms and/or treatment in the last 12 months). Recruitment was stratified by age group, sex and state according to national data for people with asthma. Participants completing the survey received 'points' from the panel provider with a value of AUD 1.50, which were redeemable for small items but not cash.

\section{Survey instrument}

The survey instrument was piloted in 600 patients. Survey questions included demographics, asthma medications (shown with images and trade names) taken in the last 12 months and the ACT, ${ }^{10}$ a five-item questionnaire assessing asthma symptom control, used under licence from the copyright holder, Optum. Urgent asthma-related healthcare for exacerbations included urgent general practitioner (GP) visits, emergency department (ED) visits and hospitalisations. For attitudes about asthma and asthma treatment, participants were asked to record their agreement using Likerttype responses ranging from 1 (strongly disagree) to 7 (strongly agree). Participants were also asked to record the proportion of their reliever inhalers that they purchased over the counter without a prescription, and the proportion with prescriptions (total 100\%).

For analysis, 'reliever-only' participants were those who did not report taking any preventer medication in the past 12 months. Asthma symptom control was classified as well controlled if ACT score was 20-25, and uncontrolled if $5-19 .^{11}$

\section{Data analysis}

Data were analysed using SAS version 9.4, SAS Institute (Cary, NC, USA). Survey weights were applied for prevalence data. $\chi^{2}$ test was used to check for differences in proportions between independent samples, and Kruskall-Wallis test for differences in non-parametric data. A 
Bonferroni correction was made for multiple testing, with $p$ values $<0.002$ considered significant.

\section{RESULTS \\ Demographic characteristics and medication use: reliever- only versus preventer users}

Of the 3033 randomly identified panel members with current asthma who were invited to complete the survey, $3018(99.5 \%)$ accepted and 2686 completed the survey (completion rate $89.0 \%$ ), with a demographic distribution that closely matched national data for people with asthma. ${ }^{18}$ Overall, 2672 reported using one or more asthma medications in the previous year and, of these, $1038(38.8 \%)$ had only used a reliever inhaler.

Reliever-only participants, compared with those who also used a preventer medication (table 1 ), were younger (median age group 30-39 years vs 40-49 years using preventer, $\mathrm{p}<0.0001)$, and a higher proportion were male $(50.7 \%$ vs $37.8 \%$ respectively, $\mathrm{p}<0.0001)$. More reliever-only participants than preventer users were current smokers, had post-school educational qualifications and higher household income, whereas fewer had a government concession card for subsidised medications.

Reliever-only participants generally used relievers less often than those taking preventers $\left(\chi^{2} \mathrm{p}<0.0001\right) ; 24.9 \%$ of reliever-only participants reported that they used their reliever 'a few times a year', compared with $15.0 \%$ of preventer users. However, $12.1 \%$ of reliever-only participants and $27.2 \%$ of those also using preventers used their reliever five or more days per week. Overall, based on ACT score, fewer reliever-only participants were classified as having uncontrolled symptoms (ACT <20) compared with those using a preventer $(38.4 \%$ vs $50.1 \%, \mathrm{p}<0.0001)$, but the distribution was heterogeneous (figure 1).

\section{Reliever-only users with urgent asthma healthcare}

Despite these apparently benign findings for reliever-only users as a whole, almost a quarter $(\mathrm{n}=242,23.3 \%)$ had required urgent healthcare for asthma in the previous 12 months. These participants were more likely to be male, hold a health concession card and be current smokers than those without urgent healthcare $(\mathrm{n}=796$, table 2$)$.

Reliever-only participants with urgent healthcare had worse asthma symptom control, with only $30.6 \%$ having well-controlled asthma (ACT $\geq 20$ ) compared with $71.0 \%$ of those with no urgent healthcare $(\mathrm{p}<0.0001)$; conversely, participants with poor current symptom control were more likely to have required any urgent healthcare in the previous year $(42.1 \%$ vs $11.6 \%, \mathrm{p}<0.0001$, figure 2$)$. Importantly, two-thirds of reliever-only users with urgent healthcare reported also having one or more non-urgent GP visits to review their asthma in the previous year, compared with only a quarter of those without urgent healthcare $(66.6 \%$ vs $26.7 \%, \mathrm{p}<0.0001)$, suggesting that there could have been opportunities for intervention by the GP.
Reliever-only users with urgent healthcare used their reliever more often $(p<0.0001)$, with $26.4 \%$ using reliever five or more days per week compared with $7.8 \%$ of those without urgent healthcare. When asked to choose the response that best described the way they used their reliever, $20.8 \%$ of those with urgent healthcare selected 'I use it regularly to prevent asthma symptoms' (with the other options being 'to treat asthma symptoms', 'when feeling that symptoms were getting worse', 'whenever (they had) an asthma attack' and 'don't know/unsure'), compared with regular use by only $5.5 \%$ of those without urgent healthcare (overall $\mathrm{p}<0.0001$ ).

Reliever-only participants with urgent healthcare: attitudes to asthma and its treatment

Reliever-only participants with urgent healthcare differed from those without urgent healthcare in many of their attitudes to asthma and its treatment (table 3).

Those with urgent healthcare thought about their asthma more often (overall $\mathrm{p}<0.0001$; often/constantly $17.4 \%$ vs $7.7 \%$; rarely $32.9 \%$ vs $53.7 \%$ ) and were more often frustrated by their asthma $(\mathrm{p}<0.0001$; some $/ \mathrm{a}$ good bit/most/all of the time $33.9 \%$ vs $10.8 \%$ ) than those without urgent healthcare. They were less likely than those without urgent healthcare to be happy with how they currently managed their asthma $(\mathrm{p}<0.0001$; agree/strongly agree $53.3 \%$ vs $72.5 \%$ ) and more likely to agree/strongly agree that they were on the lookout for a better way to manage their asthma $(\mathrm{p}<0.0001 ; 30.7 \%$ vs $16.9 \%$ for those without urgent healthcare). They were more likely than those without urgent healthcare to have personal goals to keep their asthma under control ( $65.4 \%$ vs $53.1 \%, \mathrm{p}=0.0017)$ or to discover better treatment options ( $37.2 \%$ vs $13.7 \%, \mathrm{p}<0.0001)$.

Reliever-only users with urgent healthcare were more likely than those without urgent healthcare to expect a cure for their asthma ( $\mathrm{p}=0.0007$; agree/strongly agree $35.8 \%$ vs $26.1 \%$ ). There was a trend to greater belief that 'If I don't have symptoms, I don't have asthma' among reliever-only users with versus without urgent healthcare ( $\mathrm{p}=0.004$; agree/strongly agree $24.0 \%$ vs $21.4 \%$ ).

With regard to worsening asthma, more reliever-only users with urgent healthcare were afraid of having a serious asthma attack despite taking their medication as instructed $(\mathrm{p}<0.0001 ;$ agree/strongly agree $24.4 \%$ vs $9.2 \%$ ), and they were less confident than those without urgent healthcare about their ability to intervene early to prevent worsening symptoms $(\mathrm{p}=0.0001$; agree / strongly agree $55.5 \%$ vs $70.4 \%$ ). However, they were just as likely to manage their asthma themselves in this situation rather than visit a doctor $(\mathrm{p}=0.13$; agree/strongly agree $42.9 \%$ for urgent healthcare and $47.4 \%$ for those without urgent healthcare).

Urgent asthma-related healthcare: attitudes of reliever-only users versus preventer users

Reliever-only participants with urgent healthcare differed from preventer-using participants with urgent healthcare 
Open Access

Table 1 Demographic and clinical characteristics of reliever-only and preventer-using participants

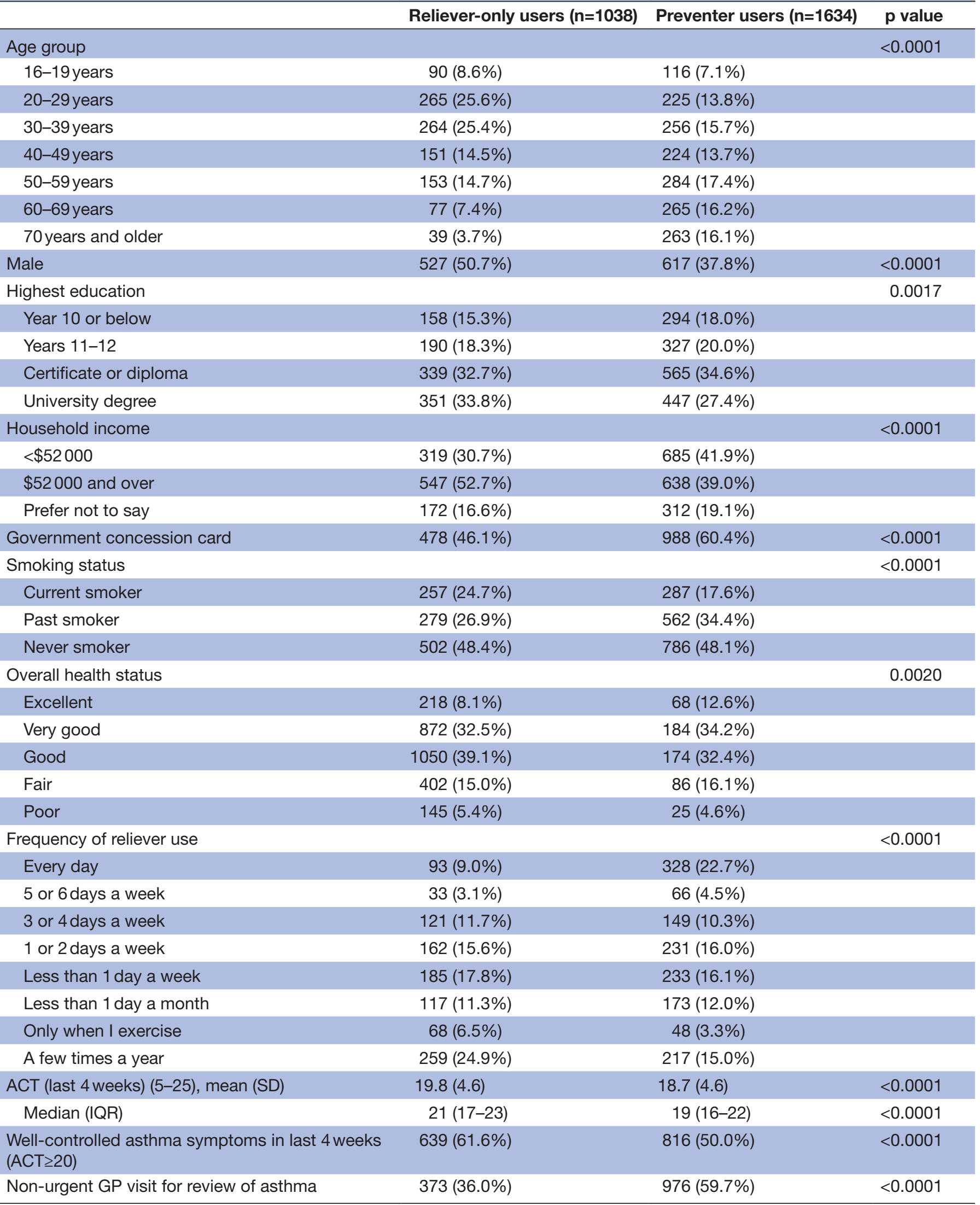

ACT, Asthma Control Test; GP, general practitioner. 


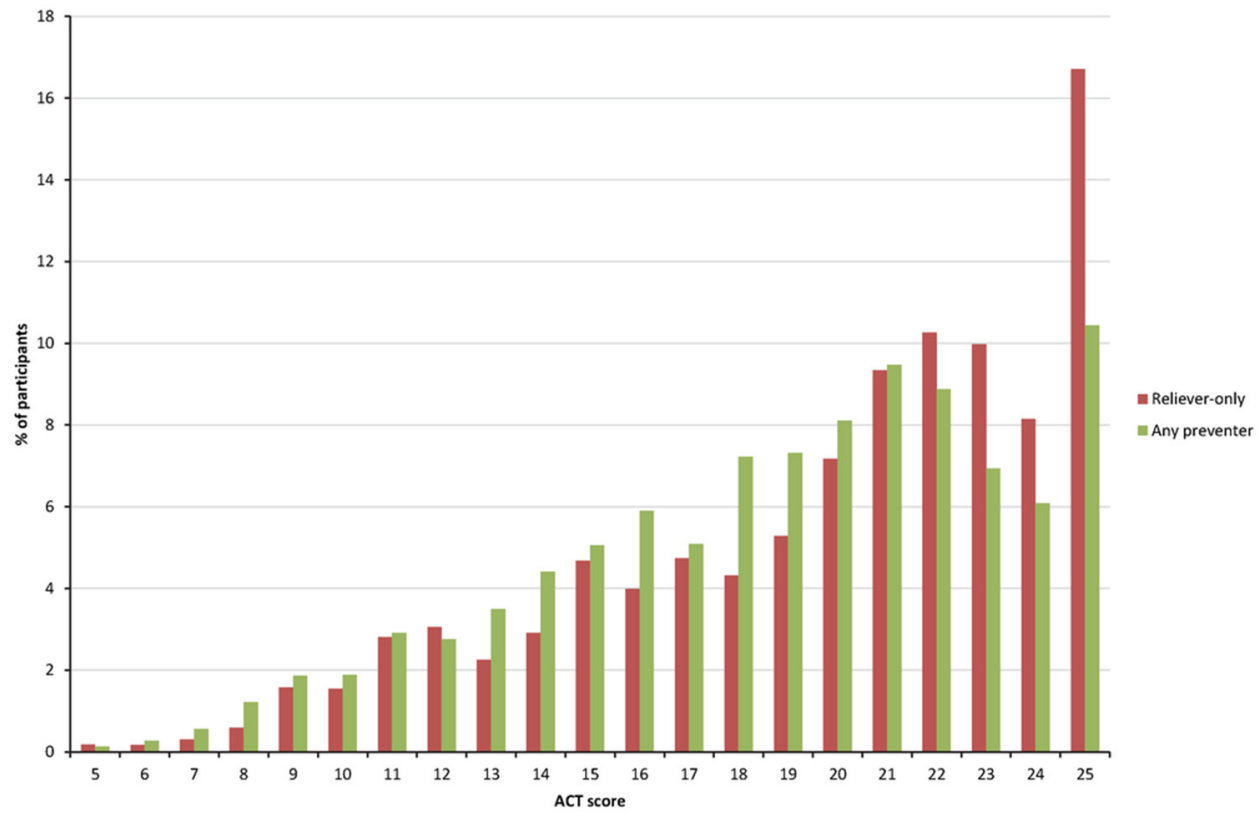

Figure 1 Distribution of asthma symptom control according to the Asthma Control Test score for reliever-only participants $(n=1038)$ and those using any preventer medication $(n=1634)$. Scores of $\geq 20$ are classified as well controlled.

in some respects: those using reliever-only were younger (median 30-39 years vs 40-49 years, $\mathrm{p}<0.0001$ ) and more likely to be male $(56.5 \%$ vs $32.5 \%, \mathrm{p}<0.0001)$ than those using preventers. However, mean ACT scores were similar (16.3 (SD 5.2) vs 16.7 (4.8), $\mathrm{p}=0.69)$.

Among participants with urgent healthcare, several major differences in attitudes and beliefs were seen between reliever-only participants and preventer users (table 3). Reliever-only users were less likely to agree that 'people don't realise how serious asthma is' $(p<0.0001$; agree/strongly agree $54.7 \%$ vs $73.8 \%$ of preventer users). When presented with the statement 'I try to ignore my asthma', only one-third of those only using reliever disagreed compared with half of preventer users ( $<<0.0001$; disagree/strongly disagree $32.3 \%$ vs $49.3 \%$ ). Reliever-only users were more likely to agree that 'If I don't have symptoms, I don't have asthma' ( $\mathrm{p}<0.0001$; agree/ strongly agree $24.0 \%$ vs $15.3 \%$ ). Responses about worsening asthma were similar for reliever-only and preventer users with urgent healthcare, except that reliever-only users were far more likely to manage worsening asthma themselves rather than visiting a doctor $(\mathrm{p}<0.0001$; agree/ strongly agree $42.9 \%$ vs $27.6 \%$ for preventer users).

\section{Over-the-counter reliever purchase}

Of the whole study population $(\mathrm{n}=2686), 56.6 \%$ of participants purchased all their relievers with a prescription, and $24.3 \%$ purchased all over the counter. As only $19.1 \%$ of participants purchased reliever both ways, responses were dichotomised at $\geq 50 \%$ or $<50 \%$ over the counter for subsequent analyses. Participants with a medication concession card were much less likely to purchase their relievers over the counter than those without a concession card $(20.8 \%$ vs $52.3 \%, \mathrm{p}<0.0001)$.
Reliever-only participants ( $\mathrm{n}=1038)$ were more likely than preventer users to buy their relievers over the counter $(47.2 \%$ vs $27.6 \%, \mathrm{p}<0.0001)$. Among reliever-only participants, those who purchased their relievers over the counter had similar levels of symptom control as those who predominantly purchased relievers using prescriptions (uncontrolled asthma symptoms: $35.9 \%$ vs $40.6 \%$ respectively, $\mathrm{p}=0.23$ ), and there was little difference in urgent healthcare use $(19.6 \%$ vs $26.6 \%$ respectively, $\mathrm{p}=0.0250$ ). However, those purchasing their relievers over the counter were less likely to have had a non-urgent GP visit for review of their asthma $(27.0 \%$ vs $44.0 \%$, $\mathrm{p}<0.0001)$.

\section{DISCUSSION \\ Principal findings}

This survey of a nationally representative population of people with asthma provides important insights into those who are only managing their asthma with reliever medication. Although some of these patients appear to have mild asthma, there was marked heterogeneity within the population, and it was a concern to find that, in the previous year, almost one-quarter of the 1038 reliever-only participants had required urgent healthcare for asthma, and only one-third had a non-urgent GP review of their asthma. Almost $70 \%$ of those needing urgent healthcare had poorly controlled asthma symptoms, and one in five predominantly used their reliever regularly to prevent symptoms. Some of the attitudes and beliefs of those with urgent healthcare suggested potential opportunities for targeted approaches: for example, compared with those without urgent healthcare, they were more 
Open Access

Table 2 Characteristics of reliever-only participants with and without urgent asthma-related healthcare in the previous 12 months

\begin{tabular}{|c|c|c|c|}
\hline & $\begin{array}{l}\text { Urgent asthma } \\
\text { healthcare }(n=242)\end{array}$ & $\begin{array}{l}\text { No urgent asthma } \\
\text { healthcare }(n=796)\end{array}$ & $p$ value \\
\hline Age group & & & 0.189 \\
\hline 16-19years & $22(9.1 \%)$ & $68(8.5 \%)$ & \\
\hline 20-29years & $72(29.9 \%)$ & $193(24.2 \%)$ & \\
\hline 30-39years & $56(23.3 \%)$ & $208(26.1 \%)$ & \\
\hline 40-49years & $29(12.1 \%)$ & $122(15.3 \%)$ & \\
\hline 50-59years & $35(14.3 \%)$ & $118(14.9 \%)$ & \\
\hline $60-69$ years & $13(5.5 \%)$ & $63(8.0 \%)$ & \\
\hline 70 years and older & $14(5.7 \%)$ & $25(3.1 \%)$ & \\
\hline Male & $136(56.5 \%)$ & $390(49.0 \%)$ & 0.0027 \\
\hline Highest education & & & 0.169 \\
\hline Year 10 or below & $50(20.9)$ & $108(13.6 \%)$ & \\
\hline Years $11-12$ & $41(16.9)$ & $149(18.7 \%)$ & \\
\hline Certificate or diploma & $68(28.1)$ & $271(34.1 \%)$ & \\
\hline University degree & $82(34.1)$ & $268(33.7 \%)$ & \\
\hline Household income (AUD) & & & 0.106 \\
\hline$<\$ 52000$ & $90(37.3 \%)$ & $229(28.8 \%)$ & \\
\hline$\$ 52000$ and over & $117(48.6 \%)$ & $429(53.9 \%)$ & \\
\hline Prefer not to say & $34(14.1 \%)$ & $138(17.4 \%)$ & \\
\hline Government concession card & $149(61.8 \%)$ & $329(41.3 \%)$ & $<0.0001$ \\
\hline Smoking status & & & 0.009 \\
\hline Current smoker & $71(29.4 \%)$ & $186(23.3 \%)$ & \\
\hline Past smoker & $69(28.8 \%)$ & $209(26.3 \%)$ & \\
\hline Never smoker & $101(41.9 \%)$ & $401(50.4 \%)$ & \\
\hline Overall health status & & & 0.0569 \\
\hline Excellent & $30(12.6 \%)$ & $67(8.4 \%)$ & \\
\hline Very good & $85(35.4 \%)$ & $309(38.8 \%)$ & \\
\hline Good & $85(35.3 \%)$ & $296(37.2 \%)$ & \\
\hline Fair & $36(14.7 \%)$ & $93(11.7 \%)$ & \\
\hline Poor & $5(2.1 \%)$ & $31(3.9 \%)$ & \\
\hline Frequency of reliever use & & & $<0.0001$ \\
\hline Every day & $46(19.0 \%)$ & $47(5.9 \%)$ & \\
\hline 5 or 6 days a week & $18(7.4 \%)$ & $15(1.8 \%)$ & \\
\hline 3 or 4 days a week & $39(16.0 \%)$ & $83(10.4 \%)$ & \\
\hline 1 or 2 days a week & $52(21.7 \%)$ & $110(13.8 \%)$ & \\
\hline Less than 1 day a week & $35(14.5 \%)$ & $150(18.9 \%)$ & \\
\hline Less than 1 day a month & $18(7.5 \%)$ & 99 (12.5\%) & \\
\hline Only when I exercise & $9(3.6 \%)$ & $59(7.4 \%)$ & \\
\hline A few times a year & $25(10.4 \%)$ & $234(29.3 \%)$ & \\
\hline ACT (last 4 weeks) (5-25), mean (SD) & $16.3(5.2)$ & $20.8(3.9)$ & $<0.0001$ \\
\hline Median (IQR) & $16(12-20)$ & $22(19-24)$ & $<0.0001$ \\
\hline Well-controlled asthma symptoms in last 4 weeks $(A C T \geq 20)$ & $71(30.6 \%)$ & $565(71.0 \%)$ & $<0.0001$ \\
\hline Non-urgent GP visit for review of asthma & $161(66.6 \%)$ & $212(26.7 \%)$ & $<0.0001$ \\
\hline
\end{tabular}

ACT, Asthma Control Test; GP, general practitioner. 


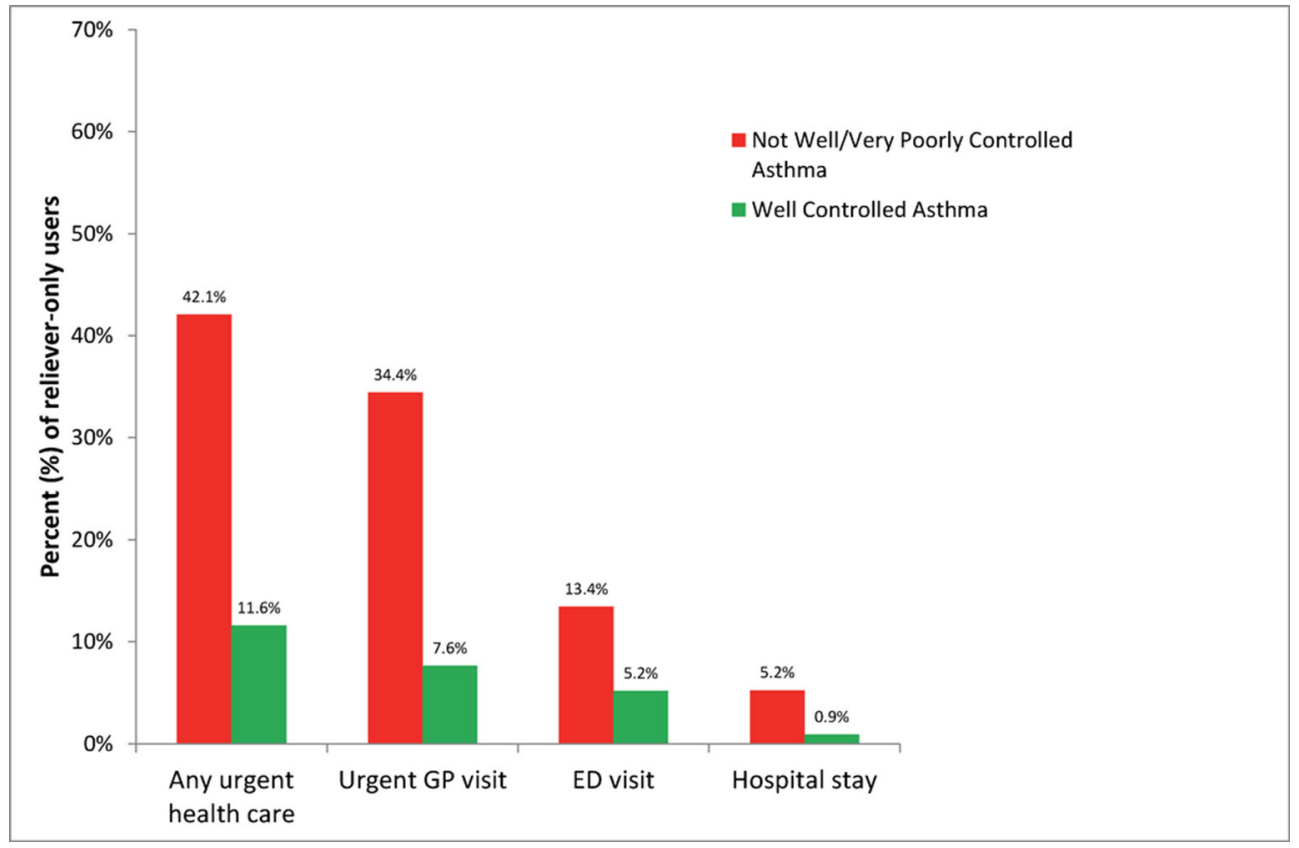

Figure 2 Urgent healthcare utilisation in the previous year by reliever-only patients $(n=1038)$, by their level of asthma symptom control: well controlled (ACT $\geq 20$, green) and not well controlled or very poorly controlled (ACT 5-15, red). $p<0.0001$ for each comparison. ACT, Asthma Control Test; ED, emergency department; GP, general practitioner.

often frustrated by their asthma, less happy with how they were managing it and more likely to be on the lookout for better treatment. Dangerously, they were less confident than those who did not require urgent healthcare about their ability to handle worsening asthma, but just as likely to try to manage it themselves; and they were far more likely than participants taking a preventer medication to try to manage worsening asthma themselves without seeing a doctor. We also found that participants obtaining their reliever over the counter did not have worse asthma control, but they were less likely to have had a non-urgent review of their asthma.

\section{Strengths and weaknesses and comparisons with other studies}

A particular strength of this study is the use of rigorous web-based methodology with three-step random sampling, which obtained a nationally representative population of people living with asthma and ensured a high completion rate $(89 \%) .{ }^{18}$ The reliability of the findings was enhanced by the high rate of home Internet access in Australia (83\%) at the time of the survey, including $59 \%$ of Australians in the lowest quintile of household income. ${ }^{19}$ The study satisfied CHERRIES requirements for reporting web-based surveys, ${ }^{20}$ and the use of a validated asthma symptom control tool allowed comparison with other asthma populations. The survey population was identified by a standard epidemiological definition of 'current asthma', that is, self-reported doctor-diagnosed asthma plus symptoms and/or asthma treatment in the last 12 months. ${ }^{21}$ Limitations, as for any survey, were that the diagnosis of asthma could not be confirmed objectively and that cross-sectional comparisons between reliever-only and preventer users may be confounded by severity. It would be a mistake to suggest from these data that preventer therapies are ineffective, given the underlying severity of disease that led to a preventer being prescribed, that poor adherence and inhaler technique may have limited its benefit and that comorbidities such as obesity may have contributed to respiratory symptoms particularly among preventer users who were older. The proportion of participants with uncontrolled asthma symptoms may be underestimated relative to the average over a year, as the survey was conducted in late spring, when there are fewer asthma exacerbations among adults. ${ }^{22}$ Importantly, the estimate of urgent healthcare among reliever-only users is a minimum, as it would exclude subjects who appropriately transitioned from reliever-only to preventer use after experiencing urgent healthcare, and those who discontinued preventer within the 12 months and subsequently required urgent healthcare.

\section{Comparison with previous studies}

The magnitude of the impact of inappropriate reliever-only treatment has been difficult to assess as clinicians are often unaware that many patients fail to renew their preventer prescriptions, ${ }^{23}$ and few population-based studies have reported standardised outcome data for reliever-only patients. Fuhlbrigge et al conducted a large US survey in $2007,{ }^{9}$ sampling representative households, with a response rate of $61 \%$; individuals could respond on behalf of others in the household, whereas the response in our study was by each individual. By comparison with the US data, a higher proportion of Australian asthma patients were reliever-only users (38.8\% vs $26.4 \%)$; however, a significant rate of acute asthma events was seen among reliever-only users in both countries-23\% 


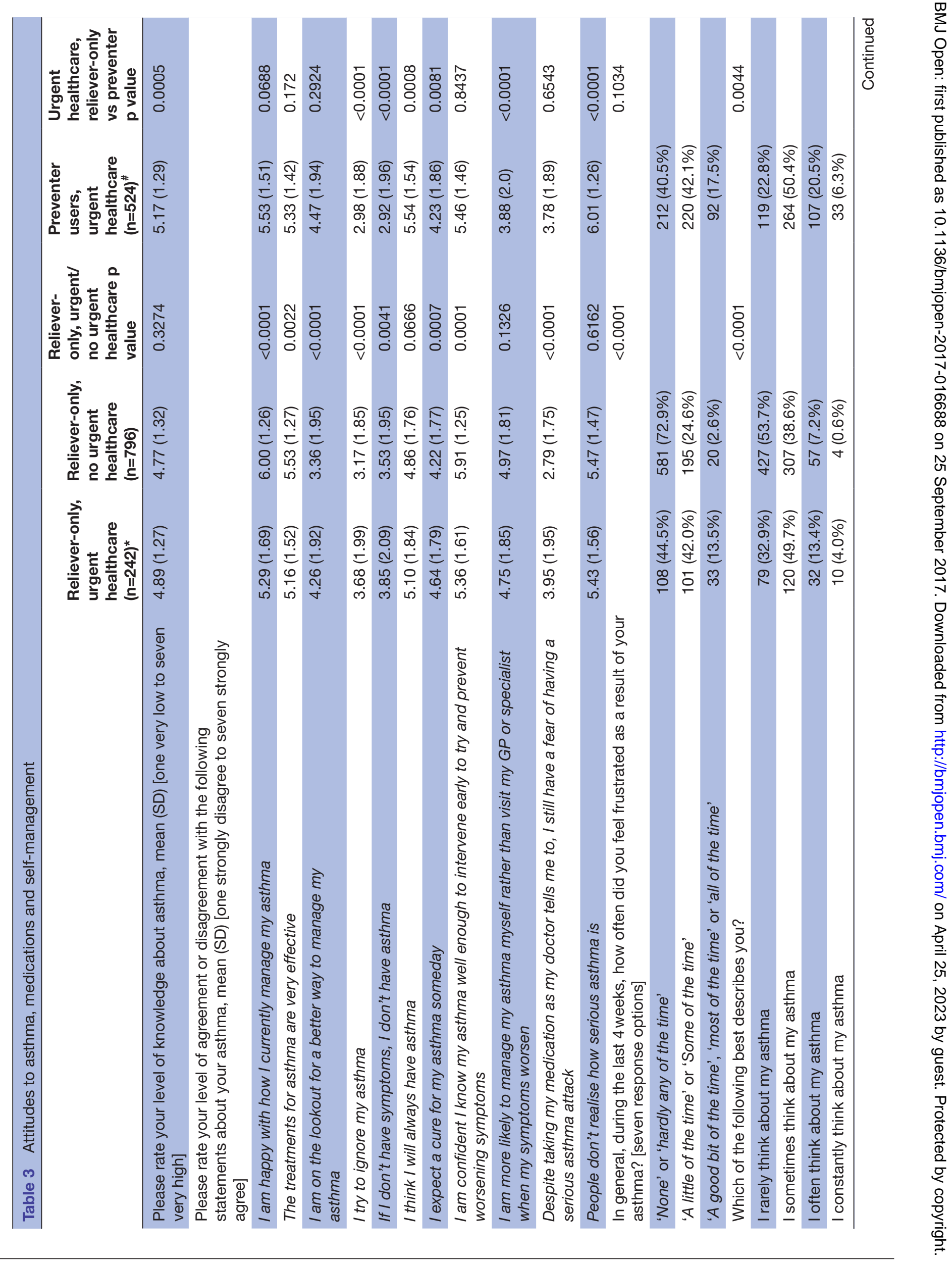




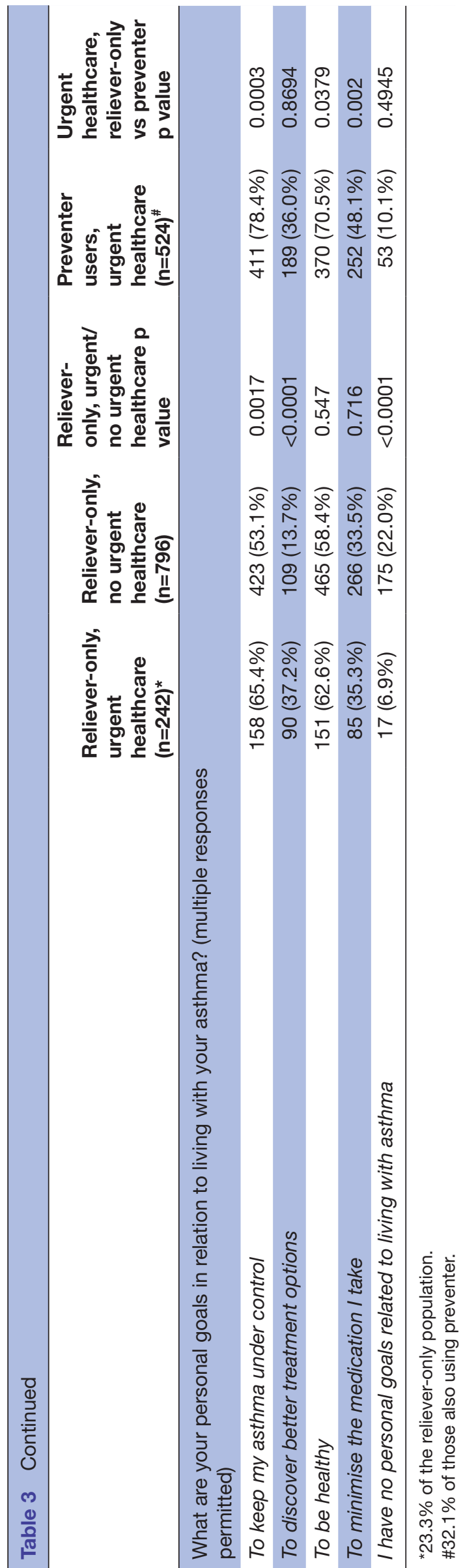

in the present study (urgent GP visit, ED visit or hospitalisation) and $31 \%$ in the US study (oral corticosteroids, ED visit or hospitalisation). Separately, the proportion of reliever-only users who had uncontrolled symptoms by ACT score was almost identical $(38.3 \%$ and $39 \%$, respectively). In a study across eight Asian countries using symptom control criteria based on the GINA report, Price et al reported that $50.2 \%$ of reliever-only participants had uncontrolled asthma and a high proportion had acute care in the previous year (oral corticosteroids: $65.8 \%$, ED: $34.0 \%$, hospitalisation: $31.8 \%){ }^{8}$

The present study also confirmed the association between uncontrolled symptoms and risk of exacerbations,${ }^{24}$ with $42 \%$ of reliever-only participants with uncontrolled symptoms in the last 4 weeks reporting urgent healthcare for asthma in the previous year. However, we emphasise that reliever-only users with infrequent symptoms should not be ignored, as $12 \%$ of participants with good current symptom control had needed urgent asthma care in the previous year (figure 2).

The differing behaviours, attitudes and beliefs expressed by reliever-only users in the present study confirm the heterogeneity of this population, but few population-based studies provide similar data for comparison. Of particular concern regarding those with urgent healthcare was their preference for managing worsening asthma themselves despite their lack of confidence in handling these situations, and the extent that reliever inhalers were overused. Overuse of SABA may itself potentially contribute to poor asthma control ${ }^{25}$ and increased risk of exacerbations ${ }^{26}{ }^{27}$ and fatal asthma, ${ }^{6}$ but delay in seeking help for asthma is also a known contributor to asthma deaths. ${ }^{28} 29$

Explanations and implications for clinicians and policymakers

For many patients, management of asthma only with a reliever medication may seem to be a reasonable approach if they have good symptom control and few risk factors for exacerbations. However, the risk of serious exacerbations can be halved with regular low-dose ICS even in patients with so-called mild asthma. ${ }^{30}$ We have shown that failure to accurately identify those who need preventer therapy, and to implement this effectively, is not a trivial issue as almost one-quarter of the reliever-only population had required urgent healthcare in the previous year. The rate of uncontrolled asthma symptoms was even higher. These problems did not appear to be due to lack of contact with the health system, as two-thirds of patients with urgent healthcare reported having one or more non-urgent GP visits for review of their asthma in the same year. However, patients may be reluctant to say that they have stopped taking their preventer. ${ }^{23}$ It also did not appear to be due to indifference on the part of the patients themselves, as they were more likely to think about, and to be frustrated by, their asthma and were seeking better asthma treatments; these group attributes, among others, suggest the potential for targeted strategies to reach these patients with key messages about asthma. 
The widespread reliance on reliever therapy without a preventer is associated with harm. Our findings indicate that this problem cannot be simply dismissed with the rationale that 'if this is what patients are prepared to accept, who am I to judge or interfere'. Change is required but may need more research to define why poor asthma control, and the risks associated with need for urgent healthcare are not being recognised for what they are and why simple, safe and effective treatment interventions are not being applied. Australia has a well-resourced and heavily subsidised healthcare system. It seems clear that patients are interested in better outcomes, but if clinicians hold a view that such patients are collectively disinterested, the necessary attention may not be applied. The rate of asthma deaths and hospitalisation in Australia has fallen dramatically since $1990,{ }^{22}$ and it is therefore possible that a degree of permissiveness or complacency has emerged towards the presence of continuing asthma symptoms and even to asthma exacerbationsas long as they are not severe or life threatening. Such a belief is inconsistent with the true effect of asthma in reliever-only subjects but may unfortunately mesh with two common patient attitudes and beliefs. The first is that, compared with those who have had acute healthcare for asthma and who report using a preventer, the reliever-only users are more likely to try to ignore their asthma, and the second is a belief that the absence of symptoms equates to an absence of asthma. Action on both sides of the doctor-patient interaction seems necessary.

\section{The issue of over-the-counter relievers}

Debate about the safety of over-the-counter SABA was recently reignited in the USA following proposals by the US Food and Drug Administration. ${ }^{16}{ }^{17}$ In Australia, SABAs have been available without prescription since 1985, but concern about this has often been expressed, given its past association with worse asthma outcomes, ${ }^{31}$ and the suggestion that some patients source relievers over the counter partly to avoid medical review. ${ }^{32}$ Ironically, this policy was nationally introduced during the 1980s epidemic of asthma deaths because of concern that deaths might be prevented by making SABAs more readily available. Ultimately, it was found that overuse of salbutamol was significantly contributing to asthma deaths at that time, particularly in young people. ${ }^{5}$ In the UK, there is very limited availability of relievers without a prescription; in the USA, inhaled epinephrine was available without prescription until recently. The present study, in a nationally representative population, confirmed the findings of a 2004 Australian pharmacy-based study that asthma control among patients purchasing overthe-counter SABA was no worse than in patients using a prescription. ${ }^{32}$ However, of concern, both studies identified patients with poorly controlled asthma who were not using a preventer medication. In the present study, this comprised around one-third of those reliever-only users who mainly purchased over the counter.

\section{Unanswered questions and future research}

For clinicians and policymakers, the present study highlights the significant burden of acute asthma exacerbations among many people who only use reliever medication. Patients using reliever-only medication are not out of sight of health professionals, as many participants with urgent healthcare also had a non-urgent GP review, and even with over-thecounter purchase in Australia, contact with a pharmacist is required. Any contact with a primary care professional (GP, nurse, pharmacist and physiotherapist) provides an opportunity for brief assessment of asthma symptom control, ${ }^{33}$ an empathic discussion about current treatment and triaging for relevant advice. Further, a quick screening tool for asthma symptom control ${ }^{1033}$ could be included, with interpretive advice, inside SABA packaging. The attitudinal data included here provide some hints towards opportunities for health professionals and patients that need to be further examined. A qualitative study of young adults with asthma ${ }^{34}$ found that those who overused reliever inhalers had adjusted poorly to the diagnosis of asthma and resented its impact on their life. The authors commented that reliever overuse 'made sense to these patients: short-acting bronchodilators were a rapid, effective, cheap 'quick-fix' for asthma symptoms', which allowed them to get back to what they were doing. ${ }^{34}$ How can we harness the frustration with asthma, the search for better treatment options, the fear of serious attacks and the lack of confidence in handling them, expressed in this survey, and link these to the implementation of modern evidencebased therapy?

The goals of asthma management are improved asthma control manifest by minimal day-to-day symptoms and reduced risk of asthma exacerbations, but we need to 'sell' this message and the means to achieve it more effectively to the large group of patients who, presently, are relying only on reliever therapy to manage their asthma.

Acknowledgements The authors acknowledge the assistance of John Lipscomb of InSync Surveys for initial statistical analysis.

Contributors HR contributed to the original survey design, drafted the analysis plan, supervised the statistical analysis and drafted and edited the manuscript. RDA contributed to the analysis plan, carried out the statistical analysis and edited the manuscript. SMS contributed to the original survey design and the analysis plan and edited the manuscript. MJP contributed to the original survey design and the analysis plan and edited the manuscript. All authors approved the final manuscript for submission.

Competing interests Dr Reddel reports grants and non-financial support from AstraZeneca during the conduct of the study; grants, personal fees and nonfinancial support from GlaxoSmithKline; grants, personal fees and non-financial support from AstraZeneca; personal fees from Merck; personal fees from Novartis; personal fees from Teva; personal fees from Mundipharma; and personal fees from Boehringer Ingelheim, outside the submitted work. She is chair of the Global Initiative for Asthma (GINA) Scientific Committee. Dr Peters reports grants and non-financial support from AstraZeneca during the conduct of the study 
and personal fees and non-financial support from AstraZeneca, personal fees from GlaxoSmithKline and personal fees from Boehringer Ingelheim, outside the submitted work. Dr Sawyer and Ms Ampon have nothing to disclose.

Patient consent Only deidentified data are included in the manuscript.

Ethics approval The study was approved by the Human Research Ethics Committee, Concord Hospital, NSW, Australia (approval CH62/6/2012-121; LNR/12/ $\mathrm{CRGH} / 153)$. All participants, as members of a web-based panel, had already provided informed consent to participate in online surveys. Informed consent for the present survey was obtained from all those agreeing to complete a survey, with participants informed on the welcome page that the survey concerned health issues, that it would take approximately 25 minutes to complete, that all responses were confidential and anonymous and that reporting would be on an aggregate level only. Consent was provided by respondents clicking the 'Go to Survey' button after reading the information about the survey.

Provenance and peer review Not commissioned; externally peer reviewed.

Data sharing statement The original analytic data set is available on request by emailing the corresponding author.

Open Access This is an Open Access article distributed in accordance with the Creative Commons Attribution Non Commercial (CC BY-NC 4.0) license, which permits others to distribute, remix, adapt, build upon this work non-commercially, and license their derivative works on different terms, provided the original work is properly cited and the use is non-commercial. See: http://creativecommons.org/ licenses/by-nc/4.0/

(c) Article author(s) (or their employer(s) unless otherwise stated in the text of the article) 2017. All rights reserved. No commercial use is permitted unless otherwise expressly granted.

\section{REFERENCES}

1. British Thoracic Society, Scottish Intercollegiate Guidelines Network British Guideline on the Management of Asthma. Edinburgh, 2016.

2. National Asthma Education and Prevention Program. Expert Panel Report 3 Asthma Care Quick Reference. Bethesda, MD: National Heart Lung and Blood Institute, 2012.

3. Suissa S, Ernst P, Kezouh A. Regular use of inhaled corticosteroids and the long term prevention of hospitalisation for asthma. Thorax 2002;57:880-4

4. Suissa S, Ernst P, Benayoun S, et al. Low-dose inhaled corticosteroids and the prevention of death from asthma. $N$ Engl $J$ Med 2000;343:332-6.

5. Abramson MJ, Bailey MJ, Couper FJ, et al. Are asthma medications and management related to deaths from asthma? Am J Respir Crit Care Med 2001;163:12-18.

6. Suissa S, Ernst P, Boivin JF, et al. A cohort analysis of excess mortality in asthma and the use of inhaled beta-agonists. Am J Respir Crit Care Med 1994;149:604-10.

7. Global Initiative for Asthma. Global Strategy for Asthma Management and Prevention. Updated 2016. Vancouver, USA: GINA, 2016.

8. Price D, David-Wang A, Cho $\mathrm{SH}$, et al. Time for a new language for asthma control: results from REALISE Asia. J Asthma Allergy 2015;8:93-103.

9. Fuhlbrigge A, Reed ML, Stempel DA, et al. The status of asthma control in the U.S. adult population. Allergy Asthma Proc 2009;30:529-33.

10. Schatz M, Sorkness CA, Li JT, et al. Asthma Control Test: reliability, validity, and responsiveness in patients not previously followed by asthma specialists. J Allergy Clin Immunol 2006;117:549-56.

11. Nathan RA, Sorkness CA, Kosinski M, et al. Development of the asthma control test: a survey for assessing asthma control. $J$ Allergy Clin Immunol 2004;113:59-65.
12. Chapman KR, Boulet LP, Rea RM, et al. Suboptimal asthma control: prevalence, detection and consequences in general practice. Eur Respir J 2008;31:320-5.

13. Prieto L, Badiola C, Villa JR, et al. Asthma control: do patients' and physicians' opinions fit in with patients' asthma control status? J Asthma 2007;44:461-7.

14. Wu AC, Butler MG, Li L, et al. Primary adherence to controller medications for asthma is poor. Ann Am Thorac Soc 2015;12:161-6.

15. Murphy KR, Meltzer EO, Blaiss MS, et al. Asthma management and control in the United States: results of the 2009 Asthma Insight and Management survey. Allergy Asthma Proc 2012;33:54-64.

16. Milgram LJ. Asthma medications should be available for over-thecounter use: con. Ann Am Thorac Soc 2014;11:975-9.

17. Gerald JK, Wechsler ME, Martinez FD. Asthma medications should be available for over-the-counter use: pro. Ann Am Thorac Soc 2014;11:975-9.

18. Reddel HK, Sawyer SM, Everett PW, et al. Asthma control in Australia: a cross-sectional web-based survey in a nationally representative population. Med J Aust 2015;202:492-6.

19. Australian Bureau of Statistics. Household Use of Information Technology, Australia, 2012-13. Canberra, Australia: ABS, 2014

20. Eysenbach G. Improving the quality of web surveys: the checklist for reporting results of internet E-surveys (CHERRIES). J Med Internet Res 2004;6:e34.

21. Pekkanen J, Sunyer J, Anto JM, et al. Operational definitions of asthma in studies on its aetiology. Eur Respir J 2005;26:28-35.

22. Australian Institute of Health and Welfare. Asthma in Australia 2011. AIHW Asthma Series no. 4.Cat. no. ACM 22. Canberra: Australian Institute of Health and Welfare, 2011.

23. Stirratt MJ, Dunbar-Jacob J, Crane HM, et al. Self-report measures of medication adherence behavior: recommendations on optimal use. Trans/ Behav Med 2015;5:470-82.

24. Haselkorn T, Fish JE, Zeiger RS, et al. Consistently very poorly controlled asthma, as defined by the impairment domain of the Expert Panel Report 3 guidelines, increases risk for future severe asthma exacerbations in the Epidemiology and Natural History of Asthma: Outcomes and Treatment Regimens (TENOR) study. J Allergy Clin Immunol 2009;124:895-902.

25. Hancox RJ, Cowan JO, Flannery EM, et al. Bronchodilator tolerance and rebound bronchoconstriction during regular inhaled beta-agonist treatment. Respir Med 2000;94:767-71.

26. Hancox RJ. Concluding remarks: can we explain the association of beta-agonists with asthma mortality? A hypothesis. Clin Rev Allergy Immunol 2006;31:279-88.

27. Stanford $\mathrm{RH}$, Shah MB, D'Souza AO, et al. Short-acting $\beta$-agonist use and its ability to predict future asthma-related outcomes. Ann Allergy Asthma Immunol 2012;109:403-7.

28. Goeman DP, Abramson MJ, McCarthy EA, et al. Asthma mortality in Australia in the 21st century: a case series analysis. BMJ Open 2013;3:e002539.

29. Royal College of Physicians. Why Asthma Still Kills. The National Review of Asthma Deaths (NRAD). Confidential Enquiry report. London: RCP, 2014.

30. Reddel HK, Busse WW, Pedersen S, et al. Should recommendations about starting inhaled corticosteroid treatment for mild asthma be based on symptom frequency: a post-hoc efficacy analysis of the START study. Lancet 2017;389:157-66.

31. Gibson P, Henry D, Francis L, et al. Association between availability of non-prescription beta 2 agonist inhalers and undertreatment of asthma. BMJ 1993;306:1514-8.

32. Douglass JA, Goeman DP, McCarthy EA, et al. Over-the-counter $\beta 2-$ agonist purchase versus script: a cross-sectional study. Respir Med 2012;106:223-9.

33. LeMay KS, Armour CL, Reddel HK. Performance of a brief asthma control screening tool in community pharmacy: a cross-sectional and prospective longitudinal analysis. Prim Care Respir J 2014;23:79-84.

34. Cole S, Seale C, Griffiths C. 'The blue one takes a battering' why do young adults with asthma overuse bronchodilator inhalers? A qualitative study. BMJ Open 2013;3:e002247. 